\title{
The HIVE: A huge immersive virtual environment for research in spatial cognition
}

\author{
David Waller, Eric Bachmann, And Eric Hodgson \\ Miami University, Oxford, Ohio \\ AND \\ ANDREW C. BEALL \\ University of California, Santa Barbara, California
}

\begin{abstract}
Research in human spatial cognition has benefited from the advent of virtual environment (VE) technology; however, few VE systems currently enable users to move realistically over large physical spaces. Here, we describe a huge immersive virtual environment (HIVE) that offers untethered tracking of users in a $570 \mathrm{~m}^{2}$ physical space. This large tracking area allows users to move through virtual worlds in the same manner in which they move in the real world and enables behavioral research in spatial cognition examining mental processes that require extensive movement through an environment. We provide a detailed description of this system, and report an experiment examining distance estimation in virtual environments that illustrates the utility of the HIVE.
\end{abstract}

In the past two decades, real-time 3D interactive computer graphics (also known as virtual environments or VEs) have been increasingly regarded as providing an effective medium for education (Winn et al., 1999), communication (Biocca, 1992), social interaction (Blascovich et al., 2002), entertainment (Badique et al., 2002), and training (Seidel \& Chatelier, 1997). Because they offer unprecedented control over stimulus characteristics and enable precise measurement of users' responses, VEs have also been used in numerous basic (Loomis, Blascovich, \& Beall, 1999) and applied (Stone, 2002) research settings. Much of the appeal of VEs in these applications derives from their ability to depict visual and spatial information as humans normally experience it - in three dimensions, from a ground level, first-person perspective.

Probably no area of psychological research has benefited as much from the advent of VE technology as has the scientific study of human spatial cognition. An increasingly large number of studies have used VEs to examine how people learn (Jacobs, Laurance, \& Thomas, 1997; Tlauka \& Wilson, 1994) and mentally represent (Christou \& Bülthoff, 1999; Rossano \& Moak, 1998; Wilson \& Péruch, 2002) spaces, and whether the knowledge acquired from interacting with a VE is comparable to that acquired in the real world (Waller, Hunt, \& Knapp, 1998; Wilson, Foreman, \& Tlauka, 1997; Witmer, Bailey, Knerr, $\&$ Parsons, 1996). Because changes in real-world environments are often beyond the control of experimenters, and because the covariation of many of the world's properties are fixed, it can be difficult, time consuming, and sometimes impossible to conduct controlled experiments in real-world environments that address the implications of theories of human navigation and spatial cognition. Computer simulated spaces, on the other hand, offer spatial cognition researchers almost complete control over the spatial properties of the environments with which users interact. Moreover, VEs are not bound by the constraints of the real world, such as three-dimensionality, Euclidean geometry, and adherence to the law of gravity. Several investigators have used VEs to examine how people respond to these nonreal-world situations in an effort to gain insight into normal human perception and cognition (D'Zmura, Colantoni, \& Seyranian, 2000; Foo, Warren, Duchon, \& Tarr, 2005; Lambrey \& Berthoz, 2003).

Despite the potential of VEs for understanding human spatial cognition, researchers currently face difficulties when using them to investigate how people learn and remember large-scale spaces. ${ }^{1}$ One of the chief difficulties with using VEs to study cognition in large-scale spaces is that many VEs do not allow users access to the body-based sources of sensory information (e.g, vestibular, proprioceptive, and efferent information) that typically inform people about their movement in and through real world spaces. For example, users of "desktop" VEs generally sit stationary before a computer monitor and control their depicted viewpoint by means of a common, but arbitrary, interface device, such as a mouse, game pad, joystick, or keyboard. Even relatively sophisticated VEs such as $\mathrm{CAVEs}^{2}$ (those in which visual images are back-projected onto the translucent walls of a small room surrounding the user) must depict navigation over long distances by means of either an interface device such as a treadmill (Holler-

D.Waller, wallerda@muohio.edu 
bach, 2002), or a movement-oriented metaphor for locomotion, such as walking in place (Slater, Usoh, \& Steed, 1994). None of these methods of simulating navigation provides users with realistic proprioceptive or vestibular information. Yet, a great deal of research has shown that this nonvisual, body-based information can be critical for fully maintaining awareness of one's orientation in the environment (Beritoff, 1965; Glasauer, Amorim, Viaud-Delmon, \& Berthoz, 2002; Israel, Chapuis, Glasauer, Charade, \& Berthoz, 1993; Jürgens, Boß, \& Becker, 1999; Klatzky, Loomis, Beall, Chance, \& Golledge, 1998; Potegal, 1982; Telford, Howard, \& Ohmi, 1995; Yardley \& Higgins, 1998). As a result, the realism and ecological validity of many desktop VEs and CAVEs fall short of one's experience with moving through large-scale environments in the real world. Moreover, this loss of ecological validity may compromise or limit the use of VEs as a tool for psychological research on the aspects of human spatial behavior that require physical movement in space.

An increasingly common type of VE, known as the immersive $\mathrm{VE}$, is generally able to incorporate most of the nonvisual sensory information that desktop VEs and CAVEs typically neglect. Immersive VEs provide visual information to users in a head-mounted display (HMD), while tracking the position and orientation of their body with a variety of sensing devices. Several authors have noted that, in principle, immersive VEs can provide a valuable tool for studying spatial cognition (see Loomis et al., 1999; Péruch \& Gaunet, 1998; Wilson, 1997). This is largely because immersive VEs exploit the user's own body as a navigational device; movement through an immersive VE can be achieved just as it is in the real world - by physically walking. This enables users of immersive VEs to have access to the additional body-based sensory information that arises from physical movement and interaction with the environment.

To date, however, surprisingly little research has used immersive VEs to simulate large-scale spaces, primarily because most immersive VE systems have a limited track- ing area and thus cannot simulate a large environment at a one-to-one scale. Although in the past decade, the size of immersive VE laboratories has steadily increased-from rooms that are a few meters in each dimension (Chance, Gaunet, Beall, \& Loomis, 1998; Whitton et al., 2005) to those as large as $60 \mathrm{~m}^{2}$ (Whitton et al., 2005) and $148 \mathrm{~m}^{2}$ (Tarr \& Warren, 2002) - all immersive VE labs currently have a "room-sized" tracking range. Limits to the tracking area generally arise for one or more of the following reasons: (1) in most systems, the user's HMD is tethered to a stationary rendering computer, (2) many tracking technologies (e.g., those based on emitting magnetic fields) have a limited range, or (3) the investigators' lab only provides a relatively small space. To circumvent these problems, some researchers have purposefully introduced linear or angular distortions into the VE system that can reduce the physical space in which the user moves (Nitzsche, Hanebeck, \& Schmidt, 2004; Razzaque, Kohn, \& Whitton, 2001). These systems rely on the fact that users are insensitive to small discrepancies between their actions and the visual depiction of those actions. If a VE system keeps track of enough of these discrepancies, it can, for example, simulate a long, straight environment, even when the user's physical path veers or moves in circles. Although promising, these approaches are likely not without artifacts; the effect of VE-induced perceptual-motor distortions on human perception has not been thoroughly investigated.

\section{OVERVIEW OF THE HIVE Functions and Benefits}

We have recently created a VE system that we call the Huge Immersive Virtual Environment (HIVE) that combines the natural interface of an immersed VE with a large tracking area that enables the simulation of relatively large spaces (see Figure 1). Users of the HIVE have free (untethered) access to a $572 \mathrm{~m}^{2}$ area $(28.5 \mathrm{~m} \times 20.1 \mathrm{~m})$ in which their position is continually monitored by an opti-

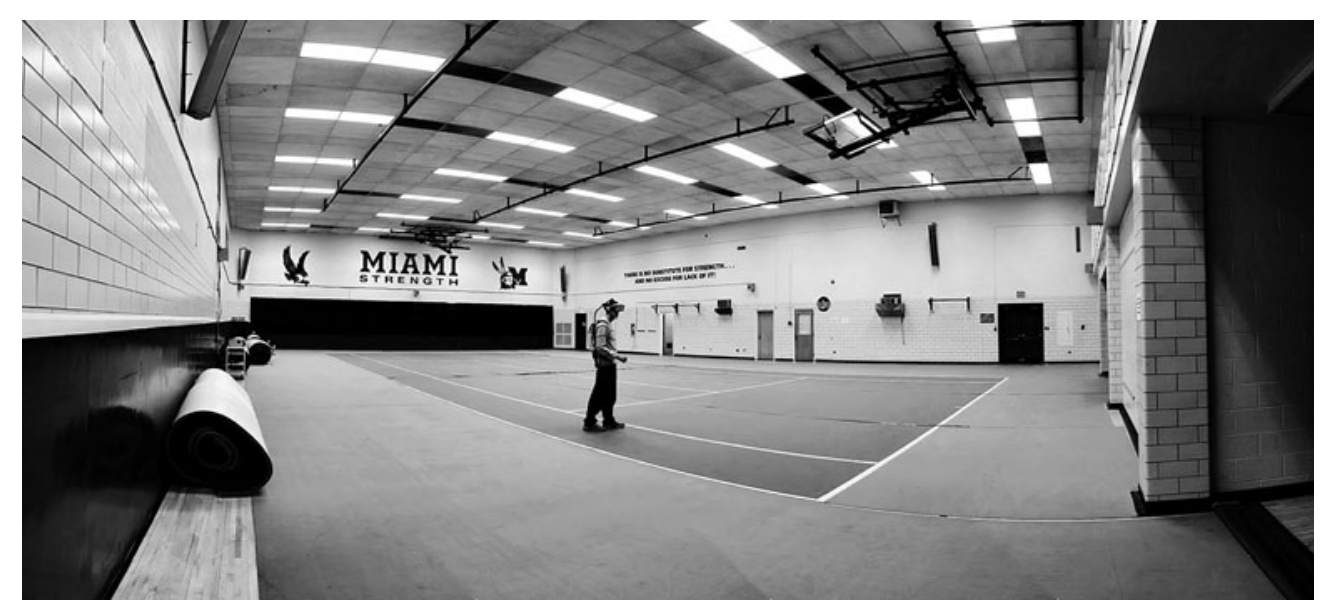

Figure 1. Photograph of the HIVE: Withrow Court, Miami University, Oxford, Ohio. Users interact wirelessly in a $28.5 \times 20.1 \mathrm{~m}$ space with computer-generated environments that they view in a head-mounted display. 
cal tracking system. Position data are sent wirelessly to a rendering computer worn by the user. This computer continually updates the user's point of view in a computergenerated environment, and displays this viewpoint in a head-mounted display (HMD) worn by the user. The orientation of the user's head is tracked by an inertial/magnetic sensor attached to the HMD. The HIVE is designed to support multiple users (or to track multiple body parts) simultaneously, although, to date, it has been used only for single users. To date, the incidence of simulator sickness (see Lawson, Graeber, Mead, \& Muth, 2002) in the HIVE has been less than $10 \%$, and is typical of the smaller immersive systems from which it was developed. Because of its large tracking area and immersive capabilities, the system provides researchers with several benefits that are not available in most other current VE systems. These benefits include the ability to investigate systematically the role of environmental scale on spatial perception and cognition, as well as to investigate mental processes that are unique to large scale spaces. After discussing each of these benefits in greater detail, we provide technical specifications of the HIVE.

\section{The Role of Environmental Scale}

One of the principle advantages to research that is provided by the HIVE is that it enables direct experimental investigations into the role of environmental scale on spatial perception and cognition. Several researchers have noted that perception of the spatial characteristics of one's immediate environment may depend on the scale of that environment. For example, Lappin, Shelton, and Rieser (2006) recently showed that participants tended to overestimate absolute egocentric distances when they were viewed in an indoor environment; however, these participants did not significantly overestimate these same distances when they were judged in an outdoor environment. Similarly, Teghtsoonian and Teghtsoonian (1970) found that the exponents of a psychophysical power function were lower when they were fit to distance estimates that were made outdoors as opposed to those that were made indoors. The reasons for these context effects are not thoroughly understood, and will likely require careful control of stimulus characteristics in both large- and small-scale spaces in order to investigate.

We recently conducted an experiment in the HIVE that illustrates its unique ability to explore the psychological effects of changes in the scale of one's environment. In particular, we examined the degree to which the perception of distances in VEs is affected by knowledge of the size of one's real-world environment. It is well known that egocentric distances (those from an observer to a target) are underestimated in immersive VEs by as much as $50 \%$ of their modeled distance (Knapp, 1999; Loomis \& Knapp, 2003; Richardson \& Waller, 2005; Thompson et al., 2004; Witmer \& Kline, 1998; Witmer \& Sadowski, 1998.) In the real world, however, estimates of egocentric distances made in comparable conditions to those in VEs can be quite veridical (Foley, Ribiero-Filho, \& Da Silva, 2003; Gibson \& Bergman, 1954; Loomis et al., 1993). The causes of distance underestimation in VEs are not fully understood, though it now seems possible that psychologi- cal factors are as influential as technological ones such as display field of view and resolution (Creem-Regehr, Willemsen, Gooch, \& Thompson, 2005; Knapp \& Loomis, 2004; Plumert, Kearney, \& Cremer, 2004).

To date, all of the research that has documented the pronounced underestimation of distances in VEs has been conducted in VEs with relatively small tracking areas. For example, Witmer and Kline (1998) had participants walk distances on a mechanically tracked treadmill while viewing a VE in a HMD and then estimate the distance that they had walked. Although participants in this experiment were asked to judge distances as great as $88 \mathrm{~m}$, they viewed these distances while facing a real-world wall that was not more than $2 \mathrm{~m}$ away from them. Knapp (1999) noted that distance underestimation in VEs may be affected by users' knowledge of the real-world environment in which they make their judgments. In an attempt to minimize this real-world knowledge, Knapp asked his participants to close their eyes before entering the lab in which they were tested, and to keep their eyes closed until they had donned the HMD. This procedure made participants unaware of the exact extent of the real-world space. Although participants continued to underestimate virtual distances under these circumstances, Knapp noted that his eye closing procedure could not eliminate participants' knowledge or awareness of the architecture of the building, and that this awareness likely constrained participants' knowledge of the size and shape of the lab room.

We used the HIVE to conduct a more controlled investigation of the hypothesis that knowledge about the extent of one's real world environment affects distance estimation in a VE. To examine this hypothesis, we closely replicated the procedures of four previous distance estimation experiments that had been run in our $8.2 \times 6.4 \mathrm{~m}$ laboratory (Richardson \& Waller, 2005, 2007). In these previous experiments, 59 participants had estimated distances between 0.50 and $5 \mathrm{~m}$ by means of a blindfolded walking task (see, for example, Loomis et al., 1993; Loomis \& Knapp, 2003; Rieser, Ashmead, Talor, \& Younquist, 1990; Thomson, 1983). On each trial, participants viewed a target post in an immersive $\mathrm{VE}$, were blindfolded (by turning off the HMD), and then asked to walk the distance to the post. On average, these participants' estimates represented only $56.01 \% \pm 4.18 \%$ (for a $95 \%$ confidence interval) of the actual distance modeled in the VE. For the present experiment, we used the same stimuli, procedures, and equipment as in the earlier experiment, and changed only the testing location, to conduct it in the HIVE. Distance estimates from participants in the HIVE $(n=16)$ averaged $50.06 \% \pm 6.61 \%$ of the actual modeled distance. The underestimation effect in the HIVE was not significantly different than that in the lab room $[t(73)=1.37$, $p=.174]$, indicating that the extent of the physical space did not significantly impact user's estimates of virtual distances. The HIVE thus enabled us to eliminate the possibility that awareness of the extent of a VE user's physical environment accounts for some of the effect of distance underestimation in immersive VEs.

In addition to enabling research on the role of scale in spatial perception, the large tracking area provided 
by the HIVE also enables researchers to understand the types of higher level cognitive representations that people acquire as a result of acting in environments of different scales. It has been suggested that people mentally represent large-scale spaces in which they can navigate differently than small-scale spaces that they can observe (Montello, 1993; Presson, DeLange, \& Hazelrigg, 1989; Weatherford, 1982). In particular, acquiring knowledge of large-scale spaces typically requires people to integrate spatial information over time, and in so doing, requires the construction of an enduring memory representation of the environment. On the other hand, tasks conducted in small, room-sized spaces may require no more than a transient and dynamic representation of one's immediate environment. Recent work in spatial cognition has shown that different psychological systems govern spatial representations, depending on whether the representations are enduring or transient (Creem \& Proffit, 1998; Easton \& Sholl, 1995; Mou, McNamara, Valiquette, \& Rump, 2004; Waller \& Greenauer, 2007; Waller \& Hodgson, 2006). By offering a facility in which investigators can control whether participants must form either an enduring mental representations of relatively large-scale environment or a transient representation of their immediate environment, the HIVE can enable greater understanding of how these types of representations differ, as well as the conditions that give rise to their establishment. For example, researchers can use the HIVE to construct VEs that differ in their spatial extent, yet are constant on other factors such as environmental complexity, the number of turns required to maneuver between locations, and the time required to navigate the environment. In this way, the HIVE enables assessment of the unique role of environmental scale in spatial cognition.

\section{Processing Large-Scale Environments}

Perhaps the greatest advantage to spatial cognition research that is provided by the HIVE is that it opens up experimental investigation of the mental structures and processes (e.g., navigation and spatial updating) that are necessary for people to interact successfully with large spaces. To date, much of the prior scientific investigation of these phenomena has been conducted in small-scale laboratory experiments (e.g., Israel et al., 1993; Jürgens et al., 1999; Telford et al., 1995) or by means of desktop computer simulations (e.g., Jacobs et al., 1997; Rossano \& Moak, 1998; Stanton, Wilson, \& Foreman, 2003; Tlauka \& Wilson, 1994) and the HIVE is uniquely poised to deepen their findings. For example, Stanton et al. (2003) used a desktop VE to examine the information humans use when taking shortcuts. The researchers concluded that, despite several prior findings to the contrary (Jacobs et al., 1997; Waller, Loomis, Golledge, \& Beall, 2000), people may not use configurations of distal landmarks to inform their navigational choices without having additional experience that links together start and goal locations (see also Chapuis, Durup, \& Thinus-Blanc, 1987). Although this is an interesting and important result, before concluding that it applies to real-world spatial learning, it would be helpful to conduct a similar experiment in a naturally scaled space in which the user actually moves, and his or her navigation is not mediated by an arbitrary interface device. Similarly, Tlauka and Wilson (1994) used a desktop VE to show that people's ability to learn a route is facilitated by the presence of landmarks, but this facilitation occurs only under cognitive load. Generalizing these findings to more naturalistic environments is an important next step, and is one that the HIVE is poised to enable. More generally, the HIVE enables reexaminations of important findings in the spatial cognition literature, with an eye toward examining (or enhancing) the ecological validity of their conclusions.

\section{TECHNICAL SPECIFICATIONS AND PERFORMANCE CHARACTERISTICS OF THE HIVE}

The HIVE is composed of several major subsystems and components as depicted in Figure 2. These include an optical position tracking system, a head-mounted display, a wearable rendering system and orientation tracking device, a graphics workstation to monitor and maintain the VE state, and system software. All processing units are linked together by an $802.11 \mathrm{~b}$ wireless network. Although these subsystems are tightly integrated, they are independent enough that individual components can be exchanged and upgraded as their technology improves. Each of the major system components is discussed in detail below.

\section{Optical Position Tracking System}

In general, optical position tracking using triangulation operates over longer distances with less interference than alternative tracking technologies such as electromagnetic and acoustic systems. Optical systems that track many points simultaneously (e.g., on the order of 100 points) are required to solve a complex problem and typically cannot perform these calculations in real time. However, position tracking of only a few points per body greatly reduces the complexity of the tracking problem. While optical methods generally suffer from a line-of-sight requirement, for applications in which tracking only single points on a limited number of users is required, system cameras can be positioned such that line-of-sight occlusions are rarely a problem.

The HIVE uses the infrared Precision Position Tracker (PPT X8) manufactured by WorldViz, LLC, for indoor position tracking over a large area. It is an eight-camera system that is capable of tracking the position of up to eight markers (infrared LEDs emitting light at $880 \mathrm{~nm}$ ) simultaneously. Currently the HIVE tracks one point on the body of each user (typically, the head). While only two cameras are needed for acquisition of marker position by the position tracker, the use of eight cameras facilitates coverage of the large tracking area, increases precision, and greatly reduces possible problems related to occlusions and estimation errors that would be associated with tracking a marker at long distances relative to the camera separation distance. The position tracking system updates position at $60 \mathrm{~Hz}$; the manufacturer indicates that the total latency for the tracker (including RS232 communication) 


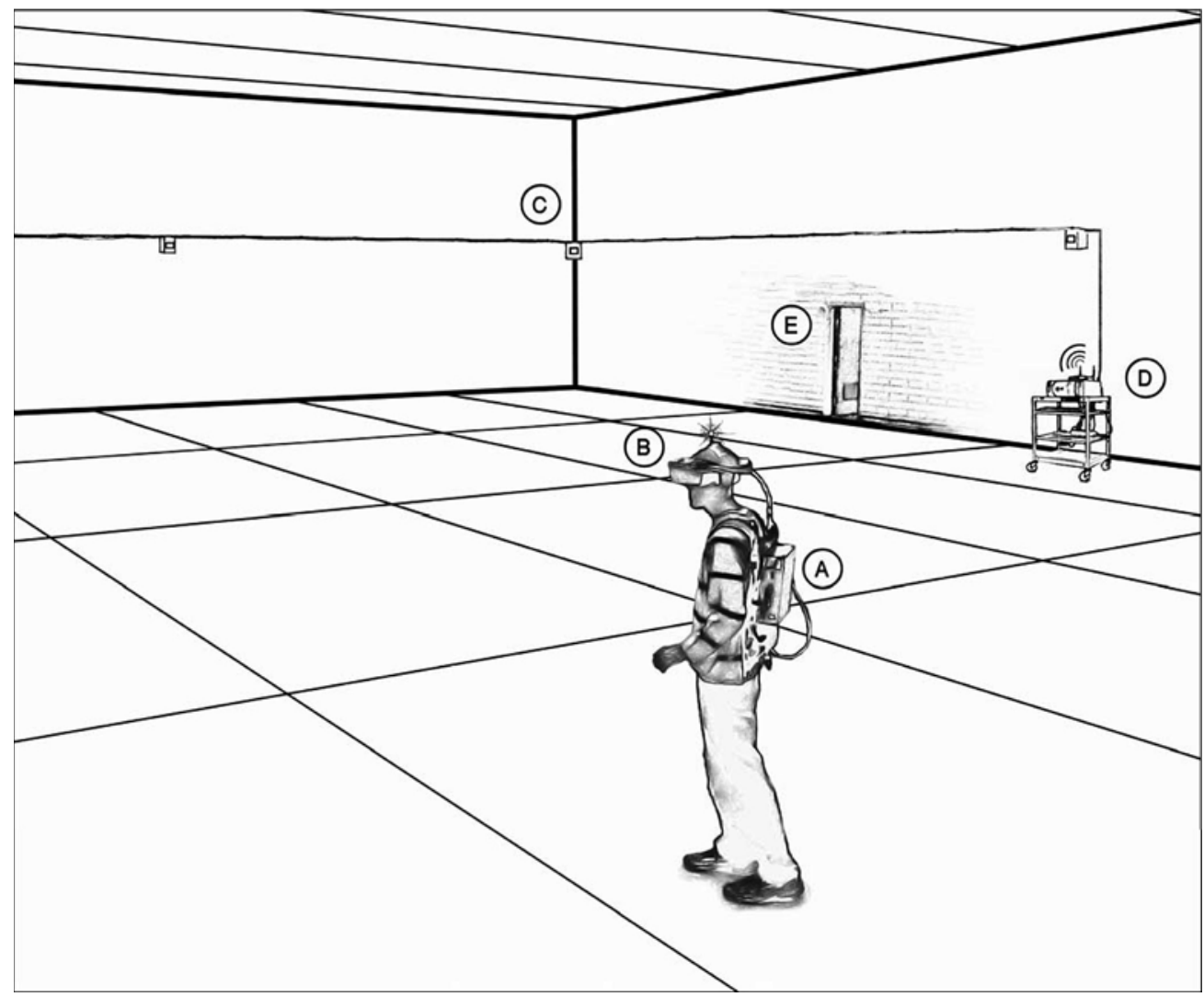

Figure 2. Schematic diagram of the HIVE components, including (A) a wearable rendering system and orientation tracking device, (B) a head-mounted display, (C) an eight-camera optical position tracking system, (D) a position tracking computer and $802.11 x$ wireless network hub, and (E) control room for the graphics workstation that monitors and maintains the VE state.

is $20 \mathrm{msec}$. The system is designed to work in cool ambient lighting (e.g., fluorescent, mercury vapor lights, and sodium vapor lights) as commonly used for large halls and exhibition rooms.

We measured the accuracy and precision of the HIVE's position tracking system along a grid of 16 (precision) or 40 (accuracy) control points that ranged over all of its tracking area. These data are displayed in Figure 3. Accuracy was generally high, especially in the center of the HIVE. For measurements within five meters of the center of the HIVE, position tracking error averaged $2.09 \mathrm{~cm} \pm 0.5 \mathrm{~cm}$ (for a 95\% confidence interval). Eighty percent of the tracking area exhibited an absolute measurement error less than $7.49 \mathrm{~cm}$, and overall RMS error was $6.68 \mathrm{~cm}$. Precision was also generally quite high. To, assess precision, we measured the variability of position estimates as they moved from and returned to the same physical point in space. This variability averaged $0.44 \mathrm{~cm} \pm 0.28 \mathrm{~cm}$ (for a $95 \%$ confidence interval). Eighty percent of the tracking area exhibited variability in position estimation less than $0.63 \mathrm{~cm}$.

\section{Head-Mounted Display}

Immersion in the HIVE is achieved by presenting computer generated images to participants in a commercially available NVIS nVisor SX HMD. The unit is a lightweight
(1 kg), dual VGA frame-parallel HMD. The HMD has a stereo display with a resolution of $1,024 \times 1,280$ for each eye. Field of view is approximately $60^{\circ}$ diagonal and $48^{\circ}$ horizontal with an angular resolution of 2.25 arcmin per pixel. Overlap between the displays is $100 \%$. The dual reflective FLCOS (ferroelectric liquid-crystal-on-silicon) displays produce 24-bit true color with a contrast ratio of 200:1. Headphones with frequency response ranging from 15 to $25,000 \mathrm{~Hz}$ are integrated into the unit. Correct synch information and voltage must be supplied to the HMD through a stereo video control unit (VCU).

\section{Wearable Rendering Computer and \\ Orientation Tracker}

Users of the HIVE are completely untethered and encumbered as little as possible. At present it is not possible to support a high-resolution HMD $(2 \times 1,024 \times 1,280)$ through wireless transmission of signals encoded in a standard video format. To overcome this limitation, HIVE users currently carry a portable rendering unit. In addition to the rendering unit, users carry an orientation sensor for head tracking, a video control unit for the HMD, and associated power supplies. The rendering computer, VCU, and power supplies are mounted to a small backpack frame (see Figure 4). The total weight of the backpack with a 


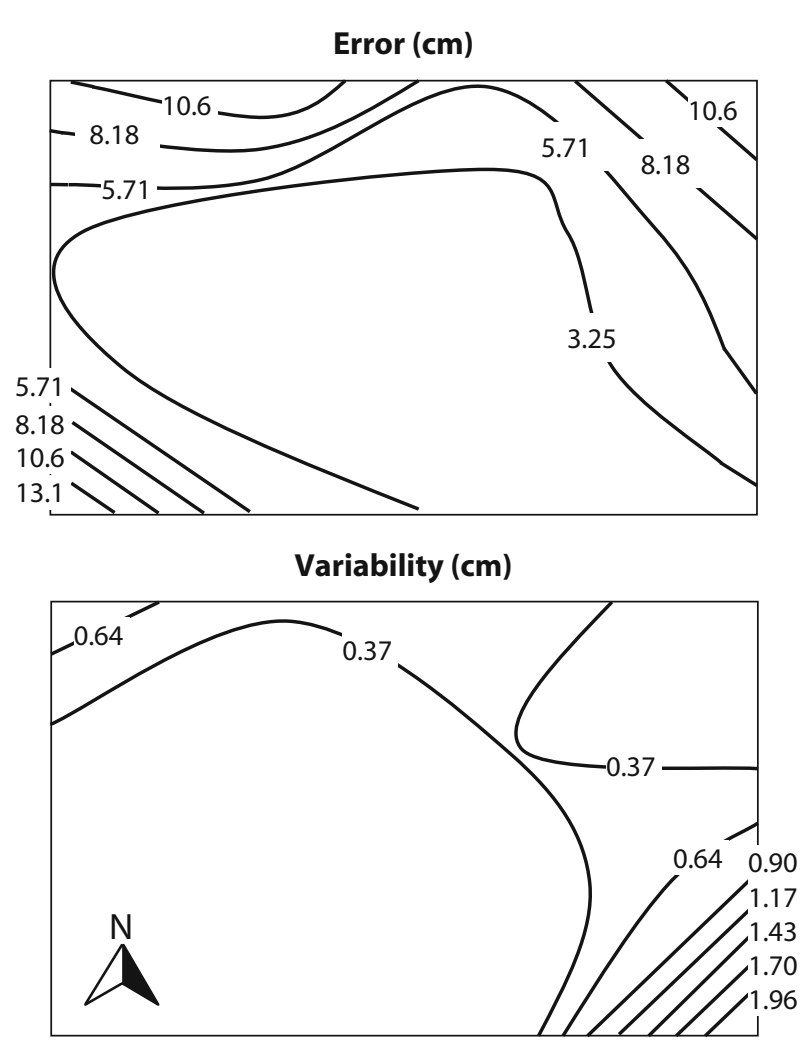

Figure 3. Overhead maps of the HIVE illustrating measured position tracking error (top) and measured position tracking variability (bottom), interpolated across a grid of observation points. Barrel distortion from the camera lenses of the optical tracking system increases measurement error to only $13 \mathrm{~cm}$ as the user approaches the edges of the tracking area. Precision is generally high, but currently reaches a maximum of $1.96 \mathrm{~cm}$ in the southeast corner of the HIVE.

single battery for HMD power is approximately $9.8 \mathrm{~kg}$. The inertial/magnetic sensor module used for tracking head orientation is connected to and powered by the wearable computer via a USB interface.

In addition to rendering graphical images and audio signals for display in the HMD, the computer carried by the user is responsible for receiving position tracking information via wireless LAN and using this position along with orientation data to update its copy of the state of the VE. These functions are currently performed by a commercial laptop computer incorporating a $2 \mathrm{GHz}$ dual core CPU with 2 GB of DDR2 system memory and an NVIDIA GeForce Go 7900 mobile graphics processing unit with $512 \mathrm{MB}$ of DDR memory. Standalone weight of the laptop computer is $3.95 \mathrm{~kg}$. For applications that only require rendering in VGA resolution, the HIVE can optionally use the Thermite computer manufactured by Quantum3D Inc (see Figure 4, label A). This unit incorporates a $1 \mathrm{GHz}$ Embedded CPU with $512 \mathrm{MB}$ of DDR system memory and an NVIDIA GeForceFX Go 5200 Mobile Graphics Processing Unit (GPU) with 64 MB of DDR Memory. External dimensions of the Thermite are $102 \times 172 \times$ $63 \mathrm{~mm}$. Standalone unit weight is $1.06 \mathrm{~kg}$.
Head orientation is tracked by an InterSense InertiaCube2 inertial/magnetic sensor module. The unit is mounted on the top rear of the HMD. Orientation estimates are made based on sensed inertial and magnetic quantities directly related to the motion of the head. The manufacturer's literature states that the InertiaCube 2 is capable of tracking orientation with an accuracy of $1^{\circ}$ in yaw and $0.25^{\circ}$ in pitch and roll. The InertiaCube 2 measures $26.2 \times 39.2 \times 14.8 \mathrm{~mm}$ and weighs $17.0 \mathrm{~g}$.

\section{VE State Computer}

The rendering and position-tracking computers are controlled and monitored through a graphics workstation. This workstation provides remote access to the computer worn by the user as well as to another workstation dedicated to the position tracking system. It enables experimenters to monitor the visualizations that are displayed in the user's HMD. HIVE software supports monitoring by creating a cluster-based network. This allows multiple viewpoints of a single virtual simulation to be rendered across more than one computer. Low-level synchronization of VE state across machines is handled automatically over the LAN via UDP packets.

\section{System Software}

Both Vizard (developed by WorldViz, LLC) and Panda3D (developed jointly by Disney and Carnegie Mellon University's Entertainment Technology Center) are currently used to support the HIVE. Both are Python-based toolkits that provide a basic framework for quickly constructing real time 3D computer-simulated environments. With support for most standard 3D model and texture formats, visual and auditory content can be easily developed with third party modeling programs. Additionally, it is straightforward to augment the rendering pipeline of either Vizard or Panda 3D with custom $\mathrm{C} / \mathrm{C}++$ code in order to handle special needs.

We have extended both Vizard and Panda 3D by implementing a HIVE application programming interface (API). The primary purpose of this API is to standardize portions of the VE software that interface with the various input devices of the HIVE, and to speed the implementation of research and other applications of the HIVE. For example, code needed to handle the initial loading of inertial and position trackers, as well as subsequent updating of the user's viewpoint based on the tracker data, is prewritten and easy to implement. The standardization further speeds development of virtual worlds to provide specialized functions that support experimental work in spatial cognition conducted in the HIVE. Specifically, functions within the API allow easy implementation of gain changes in any tracking dimension (i.e., implementing a yaw gain of $0.5^{\circ}$ would give the visual experience of turning $45^{\circ}$ if a user were to turn $90^{\circ}$ ). Other functions allow for the creation of "warp zones" that are designed to transport the user's viewpoint seamlessly between two specified points in a VE, allowing for the implementation of nonEuclidian (or otherwise impossible) environments. Finally, the API includes subroutines that are intended to protect the safety 


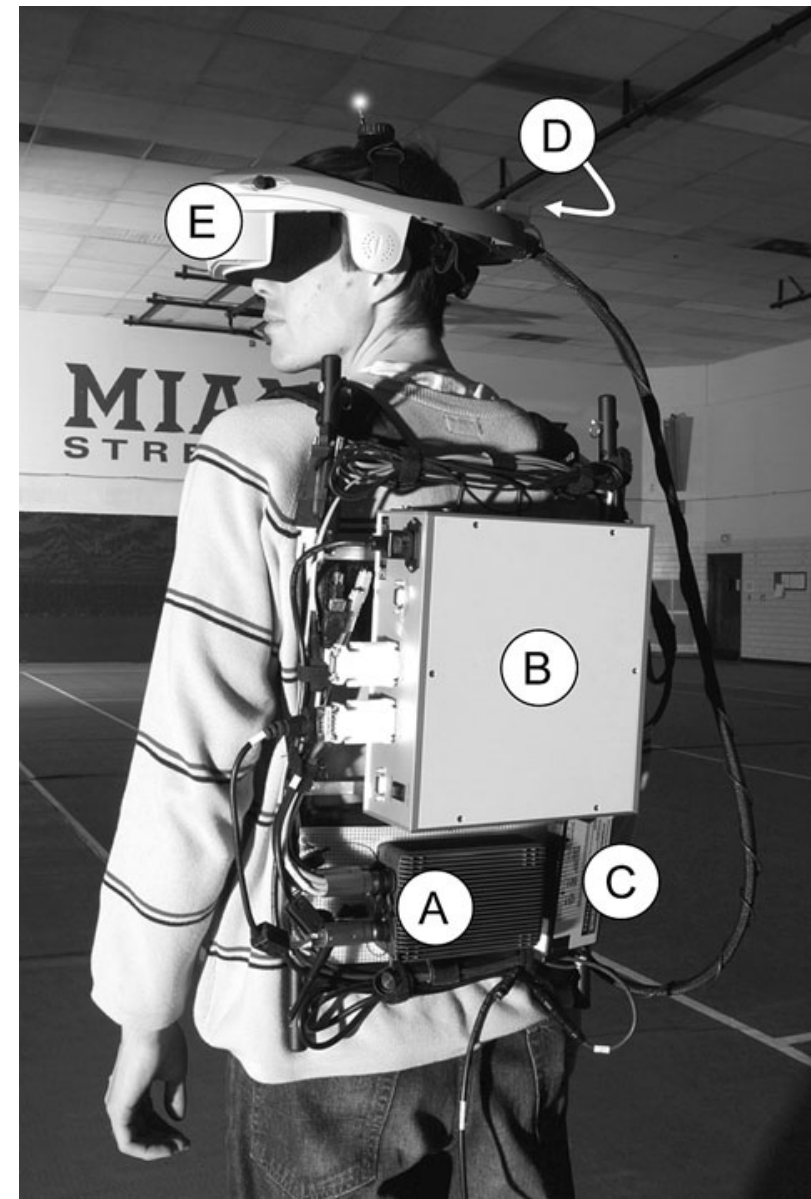

Figure 4. HIVE users wear a lightweight $(9.8 \mathrm{~kg})$ backpack on which is attached their rendering computer (A), video control unit (B), and associated power supplies (C). An inertial magnetic orientation sensor (D) is attached to users' head-mounted display (E).

of is users. For example, any environment rendered using the HIVE API will fade to black and display a warning message if a user travels too close to a physical wall.

\section{CONCLUSIONS}

Although research in human spatial cognition has benefited from VE technology, relatively few current VE systems have been able to examine effectively how people perceive, learn, and remember large-scale spaces. This is because most VE systems do not enable users to move realistically over large physical distances. The HIVE overcomes this limitation by optically tracking users' movements within a $570 \mathrm{~m}^{2}$ gymnasium. HIVE users are not tethered to a central computer, and are able to explore computer-generated environments using their own bodies as an interface device. Unlike desktop or CAVE VEs, the HIVE allows users access to body-based proprioceptive and inertial information that can inform them about their movement and orientation in space. These features of the HIVE make it ideal for (1) conducting behavioral research on the role of environmental scale in spatial perception and cognition, (2) investigating men- tal phenomena that only occur in large-scale spaces, and (3) implementing any application in which users benefit from physical movement in a large environment.

\section{AUTHOR NOTE}

This work was supported by a grant from the Defense University Research Instrumentation Program at the Army Research Office and by a Shoupp award from Miami University. We thank Adam Richardson for assistance with conducting the experiment. Correspondence should be addressed to D. Waller, Department of Psychology, Miami University, Oxford, OH 45056 (e-mail: wallerda@muohio.edu).

\section{REFERENCES}

Badique, E., Cavazza, M., Klinker, G., Mair, G., Sweeney, T., ThalmanN, D., ET AL. (2002). Entertainment applications of virtual environments. In K. M. Stanney (Ed.), Handbook of virtual environments: Design, implementation, and applications (pp. 1143-1166). Mahwah, NJ: Erlbaum.

BERITOFF, J. S. (1965). Neural mechanisms of higher vertebrate behavior. Boston: Little, Brown.

BioccA, F. (1992). Communication within virtual reality: Creating a space for research. Journal of Communication, 42, 5-22.

Blascovich, J., Loomis, J., Beall, A. C., Swinth, K. R., Hoyt, C. L., \& BAILENSON, J. N. (2002). Immersive virtual environment technology as a methodological tool for social psychology. Psychological Inquiry, 13, 103-124.

Chance, S. S., Gaunet, F., Beall, A. C., \& Loomis, J. M. (1998). Locomotion mode affects the updating of objects encountered during travel: The contribution of vestibular and proprioceptive inputs to path integration. Presence: Teleoperators \& Virtual Environments, 7, 168-178.

Chapuis, N., Durup, M., \& Thinus-Blanc, C. (1987). The role of exploratory experience in a shortcut task by golden hamsters. Animal Learning \& Behavior, 15, 174-178.

Christou, C. G., \& Bülthoff, H. H. (1999). View dependence in scene recognition after active learning. Memory \& Cogniton, 27, 996-1007.

Creem, S. H., \& Proffitt, D. R. (1998). Two memories for geographical slant: Separation and interdependence of action and awareness. Psychonomic Bulletin \& Review, 5, 22-36.

Creem-Regehr, S. H., Willemsen, P., Gooch, A. A., \& Thompson, W. B. (2005). The influence of restricted viewing conditions on egocentric distance perception: Implications for real and virtual environments. Perception, 34, 191-204.

D'Zmura, M., Colantoni, P., \& Seyranian, G. (2000). Virtual environments with four or more spatial dimensions. Presence: Teleoperators \& Virtual Environments, 9, 616-631.

EASTON, R. D., \& SHOLL, M. J. (1995). Object-array structure, frames of reference, and retrieval of spatial knowledge. Journal of Experimental Psychology: Learning, Memory, \& Cognition, 21, 483-500.

Foley, J. M., Ribeiro-Filho, N. P., \& Da Silva, J. A. (2003). Visual perception of extent and the geometry of visual space. Vision Research, 43, 2721-2733.

Foo, P., Warren, W. H., Duchon, A., \& Tarr, M. J. (2005). Do humans integrate routes into a cognitive map? Map- vs. landmark-based navigation of novel shortcuts. Journal of Experimental Psychology: Learning, Memory, \& Cognition, 31, 195-215.

Gibson, E. J., \& Bergman, R. (1954). The effect of training on absolute estimation of distance over the ground. Journal of Experimental Psychology, 48, 474-482.

Glasauer, S., Amorim, M.-A., Viaud-Delmon, I., \& Berthoz, A. (2002). Differential effects of labyrinthine dysfunction on distance and direction during blindfolded walking of a triangular path. Experimental Brain Research, 145, 489-497.

Hollerbach, J. M. (2002). Locomotion interfaces. In K. M. Stanney (Ed.), Handbook of virtual environments: Design, implementation, and applications (pp. 239-254). Mahwah, NJ: Erlbaum.

Israel, I., Chapuis, N., Glasauer, S., Charade, O., \& Berthoz, A. (1993). Estimation of passive horizontal linear whole-body displacement in humans. Journal of Neurophysiology, 70, 1270-1273.

Jacobs, J. W., Laurance, H. E., \& Thomas, K. G. F. (1997). Place 
learning in virtual space I: Acquisition, overshadowing, and transfer. Learning \& Motivation, 28, 521-541.

JÜRGENS, R., BOß, T., \& BECKER, W. (1999). Estimation of self-turning in the dark: Comparison between active and passive rotation. Experimental Brain Research, 128, 491-504.

Klatzky, R. L., Loomis, J. M., Beall, A. C., Chance, S. S., \& Golledge, R. G. (1998). Updating an egocentric spatial representation during real, imagined, and virtual locomotion. Psychological Science, 9, 293-298.

KNAPP, J. M. (1999). The visual perception of egocentric distance in virtual environments. Dissertation Abstracts International, 61, 5034B. (AAT9987005)

KNAPP, J. M., \& Loomis, J. M. (2004). Limited field of view of headmounted displays is not the cause of distance underestimation in virtual environments. Presence: Teleoperators \& Virtual Environments, 13, 572-577.

Lambrey, S., \& Berthoz, A. (2003). Combination of conflicting visual and non-visual information for estimating actively performed body turns in virtual reality. International Journal of Psychophysiology, 50, 101-115.

Lappin, J. S., Shelton, A. L., \& Rieser, J. J. (2006). Environmental context influences visually perceived distance. Perception \& Psychophysics, 68, 571-581.

Lawson, B. D., Graeber, D. A., Mead, A. M., \& Muth, E. R. (2002). Signs and symptoms of human syndromes associated with synthetic experiences. In K. M. Stanney (Ed.), Handbook of virtual environments: Design, implementation, and applications (pp. 589-618). Mahwah, NJ: Erlbaum.

Loomis, J. M., Blascovich, J. J., \& Beall, A. C. (1999). Immersive virtual environment technology as a basic research tool in psychology. Behavior Research Methods, Instruments, \& Computers, 31, 557-564.

Loomis, J. M., Klatzky, R. L., Golledge, R. G., Cicinelli, J. G., Pellegrino, J. W., \& Fry, P. A. (1993). Non-visual navigation by blind and sighted: Assessment of path integration ability. Journal of Experimental Psychology: General, 122, 73-91.

LoOMIS, J. M., \& KNAPP, J. M. (2003). Visual perception of egocentric distance in real and virtual environments. In L. J. Hettinger \& M. W. Haas (Eds.), Virtual and adaptive environments (pp. 21-46). Mahwah, NJ: Erlbaum.

Montello, D. R. (1993). Scale and multiple psychologies of space. In A. U. Frank \& I. Campari (Eds.), Spatial information theory: A theoretical basis for GIS (pp. 312-321). Berlin: Springer.

Mou, W., McNamara, T. P., Valiquette, C. M., \& Rump, B. (2004). Allocentric and egocentric updating of spatial memories. Journal of Experimental Psychology: Learning, Memory, \& Cognition, 30, 142-157.

Nitzsche, N., Hanebeck, U. D., \& Schmidt, G. (2004). Motion compression for telepresent walking in large target environments. Presence: Teleoperators \& Virtual Environments, 13, 44-60.

PÉRUCH, P., \& GAUNET, F. (1998). Virtual environments as a promising tool for investigating human spatial cognition. Current Psychology of Cognition, 17, 881-899.

Plumert, J. M., Kearney, J. K., \& Cremer, J. F. (2004, August). Distance perception in real and virtual environments. Proceedings of the First Symposium on Applied Perception in Graphics and Visualization (pp. 27-34). Los Angeles, CA.

Potegal, M. (1982). Vestibular and neostriatal contributions to spatial orientation. In M. Potegal (Ed.), Spatial abilities: Development and physiological foundations (pp. 361-387). New York: Academic Press.

Presson, C. C., Delange, N., \& Hazelrigg, M. D. (1989). Orientation specificity in spatial memory: What makes a path different from a map of the path? Journal of Experimental Psychology: Learning, Memory, \& Cognition, 15, 887-897.

Razzaque, S., Kohn, Z., \& Whitton, M. C. (2001, September). Redirected walking. Proceedings of Eurographics (pp. 289-294). Manchester, U.K.

RichARDSON, A. R., \& WALLER, D. (2005). The effect of feedback training on distance estimation in virtual environments. Applied Cognitive Psychology, 19, 1089-1108.

RichaRdSON, A. R., \& WALLER, D. (2007). Interaction with an immersive virtual environment corrects users' distance estimates. Human Factors, 49, 507-517.
Rieser, J. J., Ashmead, D., Talor, C., \& Youngquist, G. (1990). Visual perception and the guidance of locomotion without vision to previously seen targets. Perception, 19, 675-689.

Rossano, M. J., \& MoAK, J. (1998). Spatial representations acquired from computer models: Cognitive load, orientation specificity, and the acquisition of survey knowledge. British Journal of Psychology, 89, 481-497.

Seidel, R. J., \& Chatelier, P. R. (1997). Virtual reality, training's future?: Perspectives on virtual reality and related emerging technologies. New York: Plenum.

Slater, M., Usoh, M., \& Steed, A. (1994, August). Steps and ladders in virtual reality. Proceedings of the ACM Conference on Virtual Reality Software and Technology (pp. 45-54). Singapore.

Stanton, D. E. B., Wilson, P. N., \& Foreman, N. (2003). Human shortcut performance in a computer-simulated maze: A comparative study. Spatial Cognition \& Computation, 3, 315-329.

StONE, R. J. (2002). Applications of virtual environments: An overview. In K. M. Stanney (Ed.), Handbook of virtual environments: Design, implementation, and applications (pp. 827-856). Mahwah, NJ: Erlbaum.

TARR, M. J., \& WARREN, W. H. (2002). Virtual reality in behavioral neuroscience and beyond. Nature Neuroscience, 5, 1089-1092.

Teghtsoonian, R., \& Teghtsoonian, M. (1970). Scaling apparent distance in a natural outdoor setting. Psychonomic Science, 21, 215-216.

Telford, L., Howard, I. P., \& OHMI, M. (1995). Heading judgments during active and passive self-motion. Experimental Brain Research, 104, 502-510.

Thompson, W. B., Willemsen, P., Gooch, A. A., Creem-Regehr, S. H., Loomis, J. M., \& Beall, A. C. (2004). Does the quality of the computer graphics matter when judging distances in visually immersive environments? Presence: Teleoperators \& Virtual Environments, 13, 560-571.

Thomson, J. A. (1983). Is continuous visual monitoring necessary in visually guided locomotion? Journal of Experimental Psychology: Human Perception \& Performance, 9, 427-443.

Tlauka, M., \& Wilson, P. N. (1994). The effect of landmarks on routelearning in a computer-simulated environment. Journal of Environmental Psychology, 14, 305-313.

WALler, D., \& GreEnaUer, N. (2007). The role of body-based sensory information in the acquisition of enduring spatial representations. Psychological Research, 71, 322-332.

WALLER, D., \& HodGSON, E. (2006). Transient and enduring spatial representations under disorientation and self-rotation. Journal of Experimental Psychology: Learning, Memory, \& Cognition, 32, 867-882.

Waller, D., Hunt, E., \& KNAPP, D. (1998). The transfer of spatial knowledge in virtual environment training. Presence: Teleoperators \& Virtual Environments, 7, 129-143.

Waller, D., Loomis, J. M., Golledge, R. G., \& Beall, A. C. (2000). Place learning in humans: The role of distance and direction information. Spatial Cognition \& Computation, 2, 333-354.

WEATHERFORD, D. L. (1982). Spatial cognition as a function of size and scale of the environment. In R. Cohen (Ed.), New directions for child development: Vol. 15. Children's conceptions of spatial relationships (pp. 5-18). San Francisco: Jossey-Bass.

Whitton, M. C., Cohn, J. V., Feasel, J., Zimmons, P., Razzaque, S., Poulton, S. J., ET AL. (2005). Comparing VE locomotion interfaces. Proceedings of the IEEE Virtual Reality Conference (pp. 123-130). Los Alamitos, CA: IEEE.

WILSON, P. N. (1997). Use of virtual reality computing in spatial learning research. In N. Foreman \& R. Gillet (Eds.), A handbook of spatial research paradigms and methodologies: Vol. 1. Spatial cognition in the child and adult (pp. 181-206). Hove, U.K.: Psychology Press/Erlbaum.

Wilson, P. N., Foreman, N., \& Tlauka, M. (1997). Transfer of spatial information from a virtual to real environment. Human Factors, 39, 526-531.

Wilson, P. N., \& PÉRUCH, P. (2002). The influence of interactivity and attention on spatial learning in a desk-top virtual environment. Current Psychology of Cognition, 21, 601-633.

Winn, W., Hoffman, H., Hollander, A., Osberg, K., Rose, H., \& 
Char, P. (1999). Student-built virtual environments. Presence: Teleoperators \& Virtual Environments, 8, 283-292.

Witmer, B. G., Bailey, J. H., Knerr, B. W., \& Parsons, K. C. (1996) Virtual spaces and real world places: Transfer of route knowledge. International Journal of Human-Computer Studies, 45, 413-428.

WitMer, B. G., \& Kline, P. (1998). Judging perceived and traversed distance in virtual environments. Presence: Teleoperators \& Virtual Environments, 7, 144-167.

WitMER, B. [G.], \& SADOWSKI, W., JR. (1998). Nonvisually guided locomotion to a previously viewed target in real and virtual environments. Human Factors, 40, 478-488.

YARDLEy, L., \& HigGins, M. (1998). Spatial updating during rotation: The role of vestibular information and mental activity. Journal of Vestibular Research, 8, 435-442.

\section{NOTES}

1. In the literature on environmental psychology, the word "scale" is often used in its technical sense to refer to the degree to which movement is required to apprehend the spatial characteristics of an environment. Here we use the word in its related (but more colloquial) sense to indicate the spatial extent of one's environment.

2. The name CAVE is an acronym for "CAVE automated virtual environment" and is trademarked by the Illinois Board of Trustees.

(Manuscript received June 9, 2006;

revision accepted for publication September 22, 2006.) 